Check for updates

Cite this: RSC Adv., 2018, 8, 5614

Accepted 28th January 2018

DOI: 10.1039/c7ra11643h

rsc.li/rsc-advances
Received 21st October 2017

\section{Optochemical properties of gas-phase protonated tetraphenylporphyrin investigated using an optical waveguide $\mathrm{NH}_{3}$ sensor $\dagger$}

\author{
Gulimire Tuerdi, (D) ${ }^{a}$ Patima Nizamidin, ${ }^{a}$ Nuerguli Kari, (D) ${ }^{a}$ Abliz Yimit ${ }^{\star a}$ \\ and Fu Wang (iD
}

\begin{abstract}
5,10,15,20-Tetraphenylporphyrin (TPP) was synthesized, and a glass optical waveguide (OWG, which restricts and maintains the light energy in a specific, narrow space and propagates along the space axially) was coated with a gas-phase protonated TPP thin film to develop a sensor for $\mathrm{NH}_{3}$ gas detection. The results show that the TPP thin film agglomerated into $\mathrm{H}$-based $\mathrm{J}$-type aggregates after $\mathrm{H}_{2} \mathrm{~S}$ gas exposure. The molecules in the protonated TPP film OWG sensor acted as $\mathrm{NH}_{3}$ receptors because the gas-phase protonated TPP film morphologically changed from J-type aggregates into free-base monomers when it was deprotonated by $\mathrm{NH}_{3}$ exposure. In this case, $\mathrm{H}_{2} \mathrm{~S}$ gas could be used to increase the relative amount of $\mathrm{J}$-type aggregates in the TPP film and restore the sensor response. The reversible surface morphology of the TPP film was analyzed by ${ }^{1} \mathrm{H}$ NMR spectroscopy, atomic force microscopy, and UV-vis spectroscopy.
\end{abstract}

\section{Introduction}

Porphyrins are a well-known class of organic compounds that have attracted much attention owing to not only their important role in many bio-chemical processes, but also their unique electronic properties, which make them valuable reagents in the formation of functionalized molecular devices, such as porphyrin chemical sensors, ${ }^{1}$ solar cells,${ }^{2}$ and memory storage devices. $^{3,4}$ In such functionalized devices that have spectroscopic and optochemical properties, various intermolecular interactions can drive the porphyrins into specific assembled structures such as nanowires, ${ }^{5}$ nanorods, ${ }^{6,7}$ nanotubes, ${ }^{8,9}$ and nanodiscs. ${ }^{10}$ These assemblies are mostly stabilized by van der Waals forces, hydrogen bonds, $\pi-\pi$ interactions, and electronic repulsion. ${ }^{11}$ Therefore, characterizing such interactions of freebase porphyrins and correlating the structures of final assemblies through specific applications are fundamentally important for the design of free-base porphyrin assemblies. Tetraphenylporphyrin (TPP) has a square framework with four phenyl groups located perpendicular to the central ring and two free nitrogen atoms at the center of the ring. ${ }^{12}$ Since under acidic condition, the two nitrogen atoms undergo

${ }^{a}$ College of Chemistry and Chemical Engineering, Xinjiang University, Urumqi 830046, China. E-mail: ablizyimit@xju.edu.cn; Fax: +86-991-8580191; Tel: +86-991-8580191 ${ }^{b}$ Laboratory of Environmental Sciences and Technology, Xinjiang Technical Institute of Physics \& Chemistry, Key Laboratory of Functional Materials and Devices for Special Environments, Chinese Academy of Sciences, Urumqi 830011, China

† Electronic supplementary information (ESI) available. See DOI: 10.1039/c7ra11643h protonation, ${ }^{13}$ various protonated derivatives have been obtained from liquid-liquid interface ${ }^{\mathbf{1 4 - 1 6}}$ and in the gas-phase. ${ }^{\mathbf{1 7}}$ Such phenomena were investigated by UV-vis spectroscopy and monitoring the displacement of the sorption peaks, which suggested face-to-face stacking of the TPP rings and the formation of J-type aggregates. ${ }^{18}$ Interestingly, the gas-phase protonated aggregates of TPP reversed into its monomers when exposed to amine vapors. Such electronic spectral behaviors and optical properties of TPP are highly beneficial for gas sensing applications.

Detection of molecular species by optical sensing techniques is currently a topic of great interest. ${ }^{19}$ Thin film-based OWG gas sensors have two key principles: (i) the absorbance of the thin film is directly affected by the interactions with the analytes and (ii) the changes in the intensity of light reflected from the OWG thin film are related to the changes in the absorbance of the sensor, which, in turn, is affected by the interactions with the analytes. Since the major development in planar OWG sensors in the $1980 \mathrm{~s},{ }^{20-22}$ scientists have paid close attention to research and application of OWG sensors in the field of optical communication. ${ }^{23-25}$ Thin planar OWG sensors have been used for electronic and/or fluorescence detection of clinical analytes and toxic agents. ${ }^{26}$

Ammonia $\left(\mathrm{NH}_{3}\right)$ is one of the most common and harmful air pollutants that can significantly endanger human health. ${ }^{27}$ Humans can smell $\mathrm{NH}_{3}$ gas at concentrations as low as $\sim 55$ ppm. ${ }^{28}$ Exposure to even 1 ppm $\mathrm{NH}_{3}$ gas may cause irritation of the eyes, throat, and nose. Exposure to concentrations higher than 25 ppm can cause extensive lung damage as well as the burning of eyes and skin, and over 300 ppm can cause 
immediate danger to life or health. ${ }^{29}$ Analytical laboratory instruments, such as gas chromatography (GC/MS, MS, and AAS), enable the detection and quantification of $\mathrm{NH}_{3}$ with high sensitivity and resolution..$^{30}$ However, these techniques suffer from some drawbacks such as they are generally costly, cannot be used in the real field monitoring of analytes, and need experienced operators. The OWG method for analyte detection has several advantages over other types of sensors, such as the potential for high sensitivity, fast response and recovery times, anti-electromagnetic interference, remote controllability, and intrinsically safe detection. Furthermore, this type of sensors can be fabricated at a very low cost. ${ }^{31,32}$ Herein, based on the changes in the absorption spectrum of TPP and the OWG technique, we examined the performance of a free-base ТPP film ammonia sensor modified with gas-phase protonation and demonstrated the synthesis of a gas-phase protonated TPP thin film and its coating on a glass OWG as a sensing layer. $\mathrm{H}_{2} \mathrm{~S}$ gas was used as a gas-phase proton donor owing to its noticeable features such as ease of preparation, proton-richness, and most importantly, its unique gas-phase acidity compared to other hydrides ( $\mathrm{HCl}$ and $\mathrm{HBr}$ ). A highly sensitive and fast respondingrecovering gas-phase protonated TPP OWG sensor was prepared and applied in the detection of low concentrations of $\mathrm{NH}_{3}$ gas, which yielded a detection limit (40 ppb) lower than that reported for $\mathrm{NH}_{3}$ sensors in literature. ${ }^{3-37}$

\section{Experimental}

\subsection{Synthesis of 5,10,15,20-tetraphenylporphyrin}

Free-base TPP was prepared according to the method developed by Zhang et $a .^{38}$ Pyrrole was purchased from Sigma-Aldrich (USA) and all the other chemicals (analytical grade) were purchased from Tianjin Kermel Chemical Reagent Co., Ltd (China), and were used without further purification. Propionic acid $(1.63 \mathrm{~g}, 0.022 \mathrm{~mol})$ and benzaldehyde $(4.05 \mathrm{~mL}, 0.04 \mathrm{~mol})$ were added to $180 \mathrm{~mL}$ xylene and stirred for $3 \mathrm{~h}$. Pyrrole $(2.8 \mathrm{~mL}$, $0.04 \mathrm{~mol}$ ) was completely dissolved in $20 \mathrm{~mL}$ xylene and added to the previous mixture and refluxed for $3 \mathrm{~h}$ at $140{ }^{\circ} \mathrm{C}$. Xylene $(200 \mathrm{~mL})$ was removed by distillation under reduced pressure, and the crude product was purified by column chromatography (silica gel, $\mathrm{CHCl}_{3} / \mathrm{CH}_{3} \mathrm{OH}, 90: 10$ ), which yielded purple crystals (2.8 g, 45.6\%). ${ }^{1} \mathrm{H}$ NMR (Bruker AVANCE DMX400, $400 \mathrm{MHz}$, $\left.\mathrm{CDCl}_{3}, \mathrm{USA}\right) \delta 8.87(\mathrm{~s}, 8 \mathrm{H}), 8.26-8.23(\mathrm{~m}, 8 \mathrm{H}), 7.80-7.74$ $(\mathrm{m}, 12 \mathrm{H}),-2.73(\mathrm{~s}, 2 \mathrm{H})$.

\subsection{Fabrication and characterization of the film}

The gas-phase protonated TPP film OWG sensor was prepared by the following method: the sensing element was coated on a glass slide $(76 \mathrm{~mm} \times 26 \mathrm{~mm} \times 1 \mathrm{~mm}$, microscopy slide, Citotest Labware Manufacturing Co., Ltd., China) by spin-coating. Before coating, the glass slide (contains various oxides including $\mathrm{Na}_{2} \mathrm{O}, \mathrm{CaO}$, and $\mathrm{SiO}_{2}$ ) was subjected to a potassiumion $\left(\mathrm{K}^{+}\right)$exchange process via the thermal ion-exchange method, ${ }^{39}$ and the glass was immersed into molten $\mathrm{KNO}_{3}$ at $400{ }^{\circ} \mathrm{C}$ for $40 \mathrm{~min}$. The net index depends on the molar volume, ionic polarizability, and stress state created by the substitution.
In the case of $\mathrm{K}^{+}-\mathrm{Na}^{+}$exchange, as the polarizability of $\mathrm{K}^{+}$is comparably higher than that of $\mathrm{Na}^{+}$on glass, $\mathrm{K}^{+}$can be easily incorporated into glass ( $\approx 1-2 \mu \mathrm{m}$ deep), and the accompanying surface index change is lower $(n \leq 0.01)$ along with a smaller diffusion rate. ${ }^{40}$ The TPP solution $(0.07 \mathrm{wt} \%)$ was then coated onto the surface of the $\mathrm{K}^{+}$-exchanged glass OWG by using a spincoater at a rotation speed of $1850 \mathrm{rpm}$ for $30 \mathrm{~s}$. The coated sample was heated at $60{ }^{\circ} \mathrm{C}$ for $10 \mathrm{~min}$ to allow desorption of any solvent trapped in the film, and then dried in a vacuum oven for $24 \mathrm{~h}$ at room temperature. Finally, it was exposed to standard dry $\mathrm{H}_{2} \mathrm{~S}$ gas $(100 \mathrm{ppm})$ for 2 min to induce the formation of gas-phase protonated TPP film OWG sensor, and then flushed with pure nitrogen gas (99.99\%) for 2 min to clean the thin-film surface (see Fig. 1).

The changes in the refractive index, thickness, porosity, absorbance, and attenuation of the TPP thin film after exposure to $100 \mathrm{ppm} \mathrm{H}_{2} \mathrm{~S}$ gas were examined. Five different points on the TPP film surface were monitored. Mean thickness and refractive index were determined using an SGC-10 ellipsometer, the porosity of the film was calculated from Yoldas' expression, ${ }^{41}$ and the attenuation of the protonated TPP film due to absorption and scattering was measured by using the cut-back method. ${ }^{42}$ All the results are summarized in Table 2.

A theoretical calculation indicates that a $113 \mathrm{~nm}$-thick film could support the guiding mode of the transverse electric $\left(\mathrm{TE}_{0}\right)$ mode. ${ }^{43}$ Propagation of the $\mathrm{TE}_{0}$ mode in the TPP film OWG was then examined by prism coupling of a $650 \mathrm{~nm}$ laser beam. Fig. 1 shows a schematic illustration of the OWG spectroscopy setup and the idealized electric distribution of the $\mathrm{TE}_{0}$ mode. As shown in Fig. 1, when the film is irradiated with a laser beam, the OWG mode can be excited in the film, and a streak is observed on the film surface along the traveling path of the $\mathrm{TE}_{0}$ mode.

In the $\mathrm{TE}_{0}$ mode, the protonated TPP film waveguide on a glass substrate was calculated with Runge-Kutta method expressed by the following equation: ${ }^{44}$

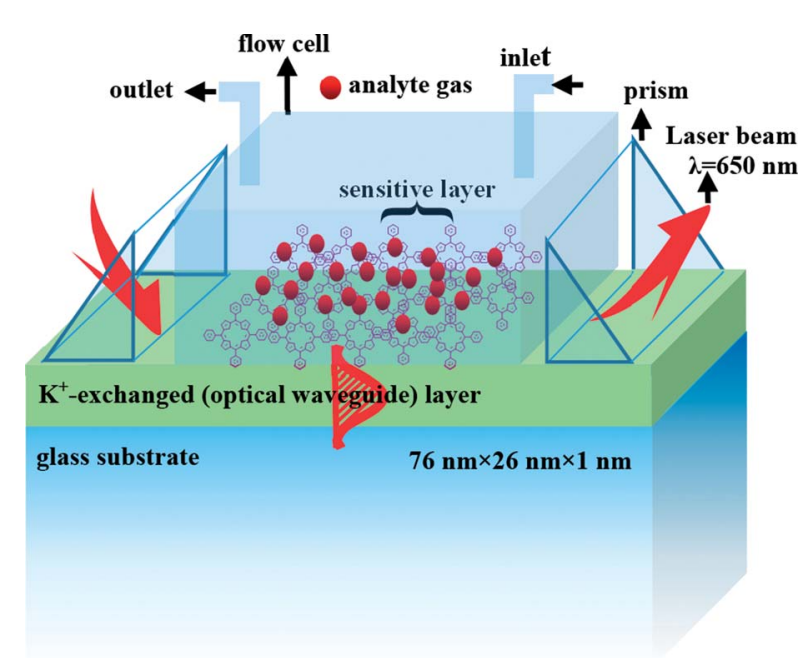

Fig. 1 Schematic illustration of a setup for gas-phase protonated TPP OWG gas sensing spectroscopy and an idealized electric distribution of the $\mathrm{TE}_{0}$ mode. 


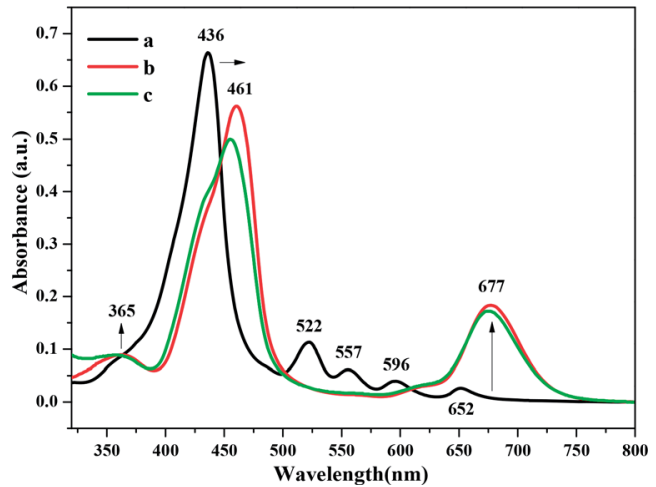

Fig. 2 Absorbance spectra of (a) TPP thin film and after exposure to 100 ppm (b) $\mathrm{H}_{2} \mathrm{~S}$ and (c) $\mathrm{HCl}$ gases.

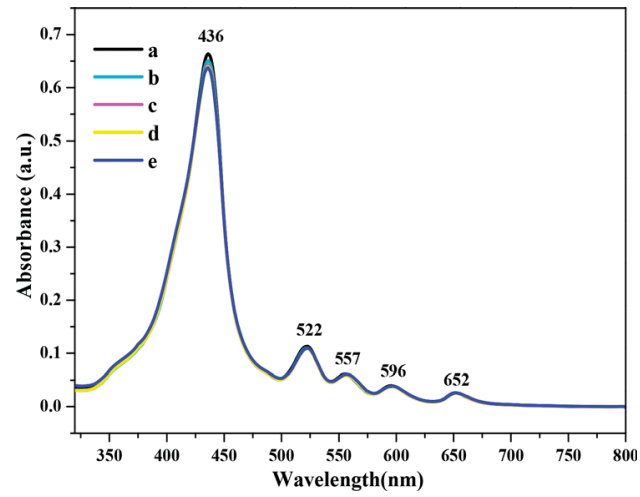

Fig. 3 Absorbance spectra of (a) TPP thin film and after exposure to saturated vapors of (b) ammonia, (c) methylamine, (d) dimethylamine, and (e) trimethylamine.

$$
S_{\mathrm{OWG}}=\left(\frac{n_{\text {surf }}^{2}}{2 N_{\text {eff }}}\right) \frac{E_{\mathrm{y}}(0)^{2}}{\int_{-\infty}^{+\infty} E_{\mathrm{y}}(x)^{2} \mathrm{~d} x},
$$

where $S_{\text {OWG }}$ is the surface sensitivity of the protonated TPP film OWG, and $n_{\text {surf }}$ and $N_{\text {eff }}$ are the average surface refractive index and effective index of the waveguide, respectively. The $n_{\text {surf }}$ is defined by $\left(n_{\mathrm{f}}^{2}+n_{\mathrm{c}}^{2}\right)^{1 / 2}$, where $n_{\mathrm{f}}$ and $n_{\mathrm{c}}$ are the refractive indexes of the protonated TPP film and cladding layer, respectively. The intensity of the electric field on the surface of the OWG is $E_{\mathrm{y}}(0)$ and the electric field distribution of the guided light is $E_{\mathrm{y}}(x)$. According to theoretical calculation ${ }^{45}$ sensitivity of the OWG reached its maximum value when the protonated TPP film mean thickness was in the range of 100-120 $\mathrm{nm}$. This result is in agreement with the choice of film thickness used in this work.

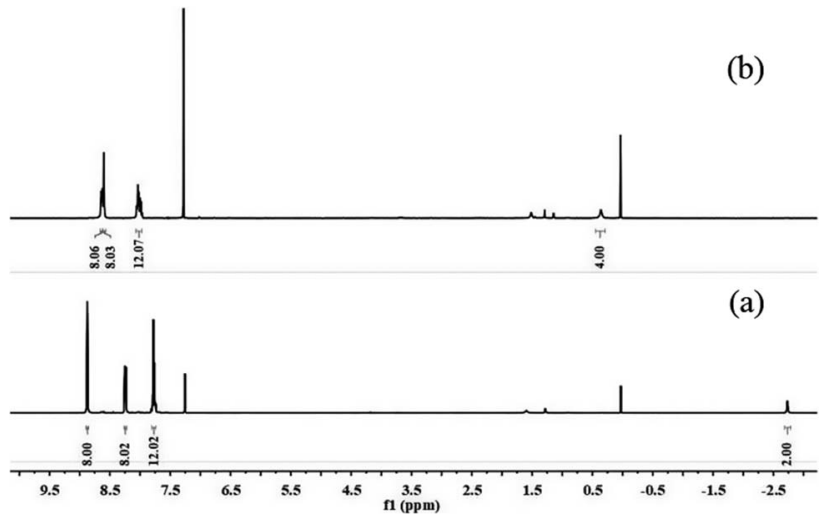

Fig. $4{ }^{1} \mathrm{H}$ NMR spectra of (a) neutral TPP and (b) gas-phase protonated TPP in $\mathrm{CDCl}_{3}$ at $298 \mathrm{~K}$.

\subsection{Gas sensing measurements}

The gas sensing apparatus ${ }^{46}$ consisted of the protonated TPP film OWG sensor, a compressed air source, a red semiconductor laser beam $(650 \mathrm{~nm})$, a flow meter, a reflector, a diffusion tube, a light detector, and a recorder. The protonated TPP film OWG sensor was attached to the prism in an index matching fluid (glass prism, $n=1.75$, matching fluid of diiodomethane, $n=1.74$ ), and irradiated by light, and then fixed to the detection cell. The intensity of the reflected light was detected by a light detector, and the signal was recorded by a computer. For each measurement, a new syringe was used to inject $20 \mathrm{~cm}^{3}$ of gas sample into the flow cell which was then vented out. In order to carry the sample gas to the sensitive layer, dry air was directed through the cell at a constant rate of $50 \mathrm{~cm}^{3} \mathrm{~min}^{-1}$. All measurements were performed at room temperature.

Standard $\mathrm{H}_{2} \mathrm{~S}$ gas was obtained by reacting a given amount of $\mathrm{FeS}$ with $\mathrm{HCl}$ at room temperature and normal pressure, and the produced $\mathrm{H}_{2} \mathrm{~S}$ gas was allowed to flow into a standard vessel $\left(600 \mathrm{~cm}^{3}\right)$. Standard $\mathrm{NH}_{3}$ gas was obtained by vaporizing a given amount of ammonia solution (25-28\%) inside a standard vessel $\left(600 \mathrm{~cm}^{3}\right)$. The concentrations of $\mathrm{H}_{2} \mathrm{~S}$ and $\mathrm{NH}_{3}$ gases were confirmed using commercial $\mathrm{H}_{2} \mathrm{~S}$ and $\mathrm{NH}_{3}$ gas detection tubes (working range of 2-200 ppm, Gastec, Beijing Municipal Institute). Different amounts of standard $\mathrm{NH}_{3}$ gas were diluted with dry air in a second standard vessel $\left(600 \mathrm{~cm}^{3}\right)$ in order to obtain the desired concentrations. Using this standard vessel-dilution method, a very low concentration of $\mathrm{NH}_{3}(0.1$ ppm) could be obtained.

Table 1 Bonding energies $\left(E_{0}\right)$ of aqueous solutions, and molar refractivity values $\left(R_{\mathrm{D}}\right)$ and atomic gas-phase acidities $\left(\Delta H_{\text {acid }}\right)$ of $\mathrm{HCl}$ and $\mathrm{H}_{2} \mathrm{~S}$ gases (298 K)

\begin{tabular}{lllll}
\hline Aqueous solution & Bonding energy $E_{0}\left(\mathrm{~kJ} \mathrm{~mol}^{-1}\right)^{49}$ & Molecule & $R_{\mathrm{D}}\left(\mathrm{cm}^{3} \mathrm{~mol}^{-1}\right)^{48}$ & $\Delta H_{\text {acid }}\left(\mathrm{kJ} \mathrm{mol}^{-1}\right)^{50}$ \\
\hline $\mathrm{H}_{2} \mathrm{O} \cdots \mathrm{HCl}$ & -15.55 & $\mathrm{HCl}$ & 12.81 & 1400 \\
$\mathrm{H}_{2} \mathrm{O} \cdots \mathrm{H}_{2} \mathrm{~S}$ & -7.28 & $\mathrm{H}_{2} \mathrm{~S}$ & 18.16 & 1474
\end{tabular}



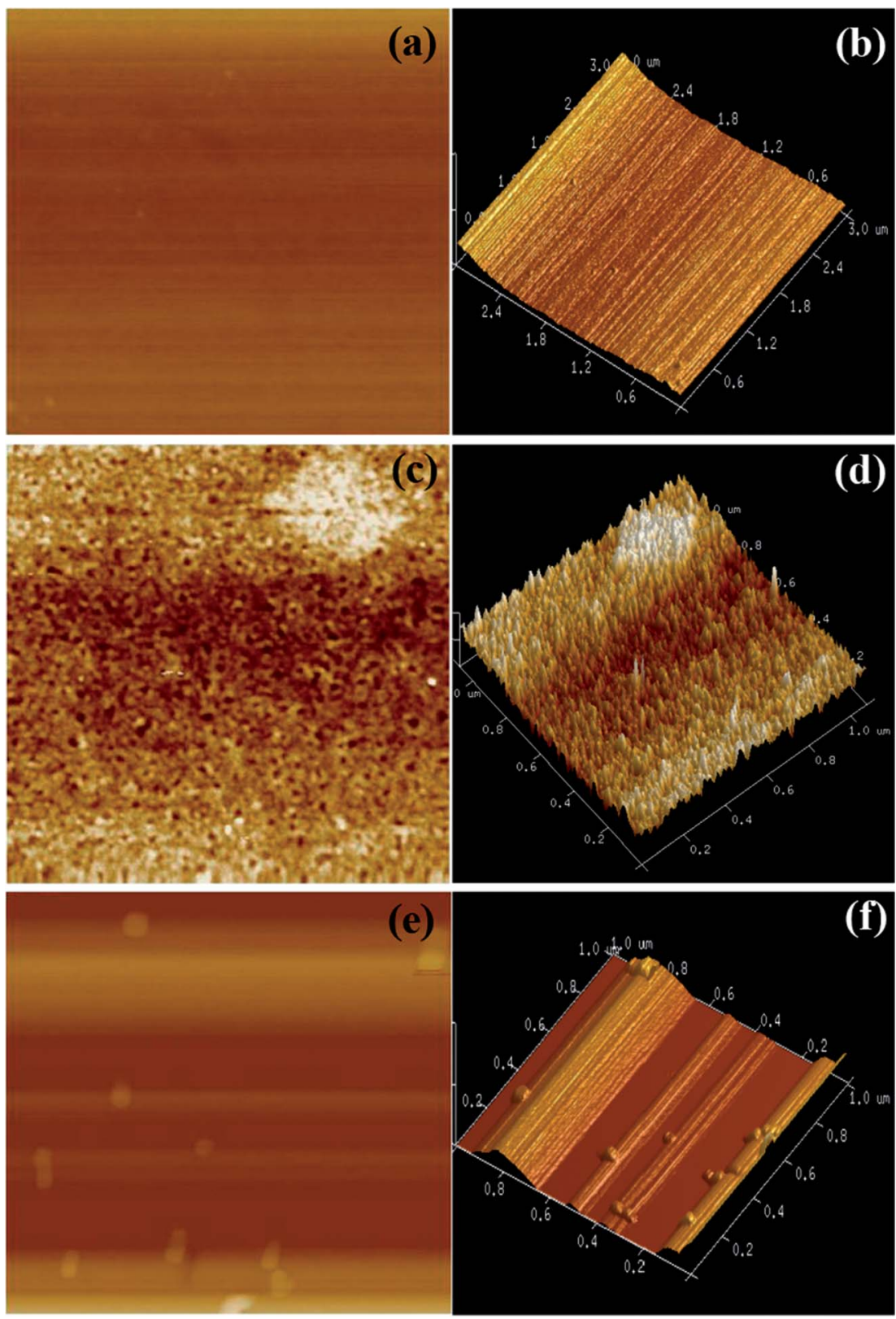

Fig. 5 AFM surface morphologies of the sensitive layer: (a) 2D and (b) 3D images of untreated TPP film, (c) 2D and (d) 3D images of TPP film after treatment with $\mathrm{H}_{2} \mathrm{~S}$ gas, and (e) $2 \mathrm{D}$ and (f) $3 \mathrm{D}$ images of gas-phase protonated film after treatment with $\mathrm{NH}_{3}$ gas.

\section{Results and discussion}

\subsection{Characterization of protonation of TPP film under gas- phase condition}

The film was characterized by optical absorption (UV-1780, Shimadzu Technology Co. Ltd, China) and ${ }^{1} \mathrm{H}$ NMR spectroscopy. Atomic force microscopy (AFM) was performed using a Multimode 8 system (Bruker, USA) to characterize the surface morphologies of the TPP thin film before and after exposure to the analytes.

The UV/vis absorption spectra was performed to characterize the protonated TPP film under gas-phase condition before and after exposure to the analytes, as shown in Fig. 2 and 3. We can see that before exposure to $\mathrm{H}_{2} \mathrm{~S}$ and $\mathrm{HCl}$, the typical absorption spectrum of TPP contains a Soret band at $436 \mathrm{~nm}$ and Q bands at 522, 557, 596, and $652 \mathrm{~nm}$ (see Fig. 2). The TPP thin film absorption spectra show a significant change after exposure to $\mathrm{H}_{2} \mathrm{~S}$ and $\mathrm{HCl}$ gases. As we can see from Fig. 2, first, the Soret band at $436 \mathrm{~nm}$ shifted to $461 \mathrm{~nm}$ when the film was exposed to analytes and demonstrated a pronounced broadening. Second, there a slight increase in intensity of the peak observed at $365 \mathrm{~nm}$, while the peak at $677 \mathrm{~nm}$ increased obviously. The redshifting of the Soret band suggests that when the TPP thin film was exposed to acidic gases, the porphyrin monomers underwent J-type aggregation, wherein the monomers were arranged in a head-to-tail fashion. ${ }^{47}$ However, no noticeable differences 


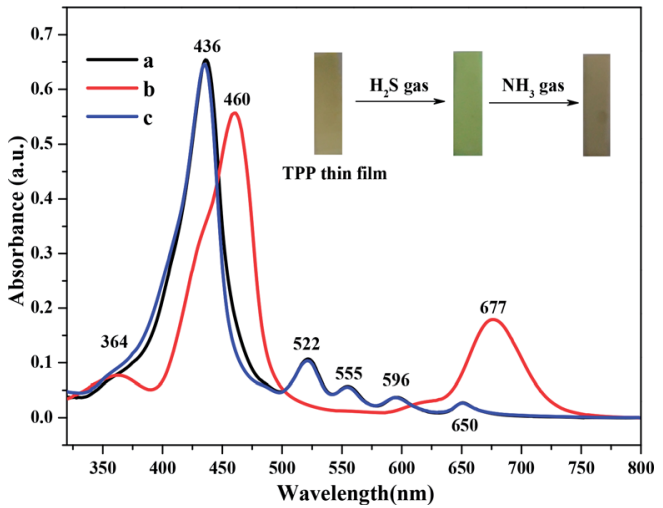

Fig. 6 Absorption spectra of (a) TPP film, (b) thin film exposed to $\mathrm{H}_{2} \mathrm{~S}$ gas (100 ppm), and (c) gas-phase protonated thin film exposed to $\mathrm{NH}_{3}$ gas (100 ppm).

in the intensities of the Soret band or Q bands were observed in the UV/vis spectra of the TPP film after exposure to amine vapors, as shown in Fig. 3.

The degree of deprotonation in gas-phase reactions, including proton transfer reactions, is measured in terms of gas-phase acidity, defined as the enthalpy of deprotonation $\left(\Delta H_{\text {acid }}\right)$. Further, Fig. 2 indicates that there were minor differences in the intensities of the absorbance peaks for the sensitive film exposed to $\mathrm{HCl}$ and $\mathrm{H}_{2} \mathrm{~S}$ gases. Although the bonding energy of $\mathrm{HCl}$ is higher than that of $\mathrm{H}_{2} \mathrm{~S}$ in aqueous solution, as shown in Table 1, both the $\Delta H_{\text {acid }}$ and molar refractivity $\left(R_{\mathrm{D}}\right)$ of $\mathrm{H}_{2} \mathrm{~S}$ are greater than those of $\mathrm{HCl}$, with the $R_{\mathrm{D}}$ of a gas being proportional to its adsorption. ${ }^{48}$ This indicates that a greater number of $\mathrm{H}_{2} \mathrm{~S}$ gas molecules were adsorbed onto the thin film surface compared to $\mathrm{HCl}$ gas, and provided protons to the TPP monomers.

In order to elucidate the protons that were transferred from the gas-phase to the TPP monomer, ${ }^{1} \mathrm{H}$ NMR spectroscopy was performed on the TPP solution (0.07 wt $\%)$ in deuterated chloroform $\left(\mathrm{CDCl}_{3}\right)$ after the treatment of the active TPP monomer with the analyte gas. The injection of high concentration of $\mathrm{H}_{2} \mathrm{~S}$ gas $\left(\approx 10^{4} \mathrm{ppm}\right)$ caused a noticeable change in the ${ }^{1} \mathrm{H}$ NMR spectrum of the TPP thin film, as shown in Fig. 4. Fig. 4 presents the ${ }^{1} \mathrm{H}$ NMR spectral data of the neutral and protonated forms of TPP. In $\mathrm{CDCl}_{3}$, TPP exhibited a chemical shift of $-2.73 \mathrm{ppm}$, which is related to the pyrrolic NH protons (see Fig. 4a). ${ }^{51}$

Table 2 Changes in refractive index, thickness, and absorbance of TPP sensing film after exposure to various gases $(\lambda=650 \mathrm{~nm})^{a}$

\begin{tabular}{|c|c|c|c|c|c|}
\hline Samples & $\begin{array}{l}\text { Refractive } \\
\text { index }(n)\end{array}$ & $\begin{array}{l}\text { Thickness } \\
(\mathrm{nm})\end{array}$ & $\begin{array}{l}\text { Absorbance } \\
(\Delta \text { Abs })\end{array}$ & Porosity & $\begin{array}{l}\text { Attenuation } \\
\left(\mathrm{dB} \mathrm{mm} \mathrm{mm}^{-1}\right)\end{array}$ \\
\hline TPP film & 1.6324 & 111.95 & - & - & - \\
\hline $\begin{array}{l}\text { Protonated TPP } \\
\text { film }\end{array}$ & 1.7757 & 118.31 & 0.057 & $22.68 \%$ & 5.42 \\
\hline $\begin{array}{l}\text { After exposure } \\
\text { to } \mathrm{NH}_{3}\end{array}$ & 1.6302 & 110.31 & 0 & - & - \\
\hline
\end{tabular}

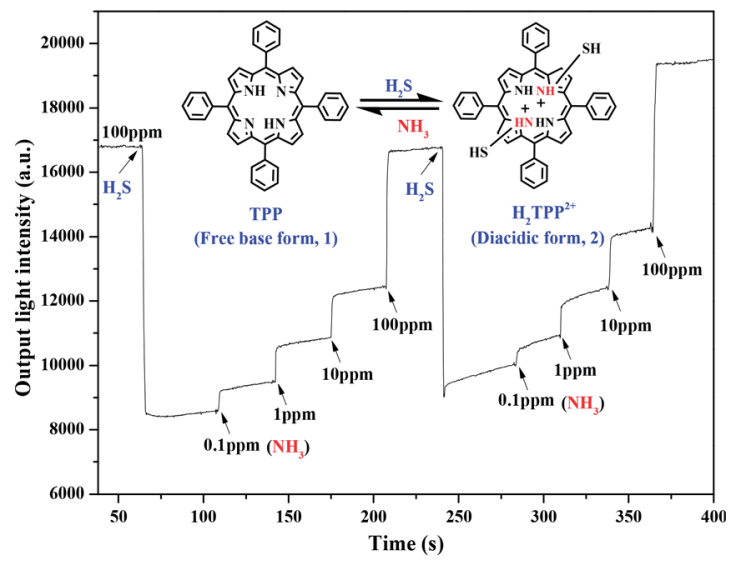

Fig. 7 Evolution of response of protonated TPP thin film upon exposure to $\mathrm{NH}_{3}$ gas.

However, for $\mathrm{H}_{2} \mathrm{~S}$ treatment, the pyrrolic $\mathrm{NH}$ protons resulted in a shift of $0.26 \mathrm{ppm}$ (see Fig. 4b). In addition, the broad $\beta$-pyrrolic $\mathrm{CH}$ resonance shifted from $7.72 \mathrm{ppm}$ to $8.01 \mathrm{ppm}$. At the same time, the two resonances at $8.25 \mathrm{ppm}$ and $8.85 \mathrm{ppm}$ (see Fig. 4a) merged into a single resonance observed at 8.65 ppm (see Fig. 4b). These changes indicated that strong hydrogen bonding was responsible for the up-field shift in the ${ }^{1} \mathrm{H}$ NMR resonance arising from the inner $\mathrm{NH}$ protons. ${ }^{52}$

The AFM images of the TPP-coated glass slide were obtained in the tapping mode both before and after exposure to $\mathrm{H}_{2} \mathrm{~S}$ and $\mathrm{NH}_{3}$ gases. We can see from Fig. $5 \mathrm{a}$ and $\mathrm{b}$ that the film is relatively dense and smooth before exposure to $\mathrm{H}_{2} \mathrm{~S}$. After exposure of $\mathrm{H}_{2} \mathrm{~S}$ gas, nanosized aggregates were observed on the film surface (see Fig. $5 c$ and d), whereas no such aggregates were detected in the unexposed TPP film. It is evident from the images that the TPP monomers on the film surface aggregated in the gas-phase after exposure to $\mathrm{H}_{2} \mathrm{~S}$ gas. Furthermore, the high-magnification 3D view (see Fig. 5d) shows that the TPP aggregates grew vertically, and bundles of small nanorods of TPP assembled in a parallel manner, producing the nanosized aggregates. This observation is in agreement with that in a previous report. ${ }^{53}$ However, significant structural changes

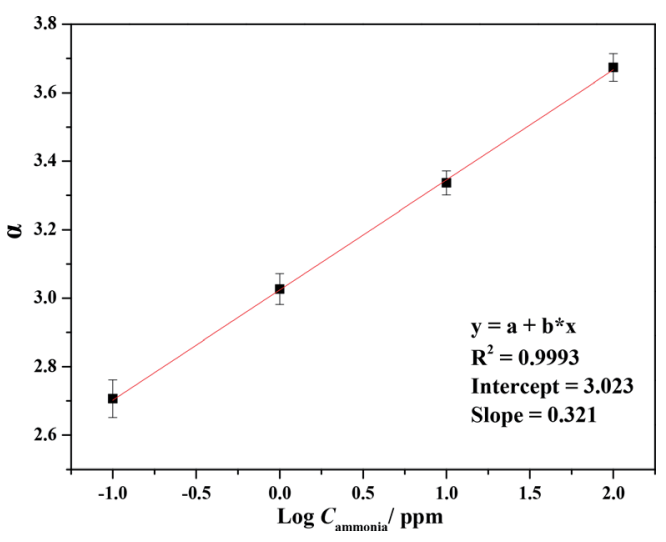

Fig. 8 Relationship between sensor signal and $\mathrm{NH}_{3}$ vapor concentration. 
Table 3 Ammonia detection performance of gas-phase protonated TPP OWG sensor developed herein and those of other types of porphyrin ammonia sensors

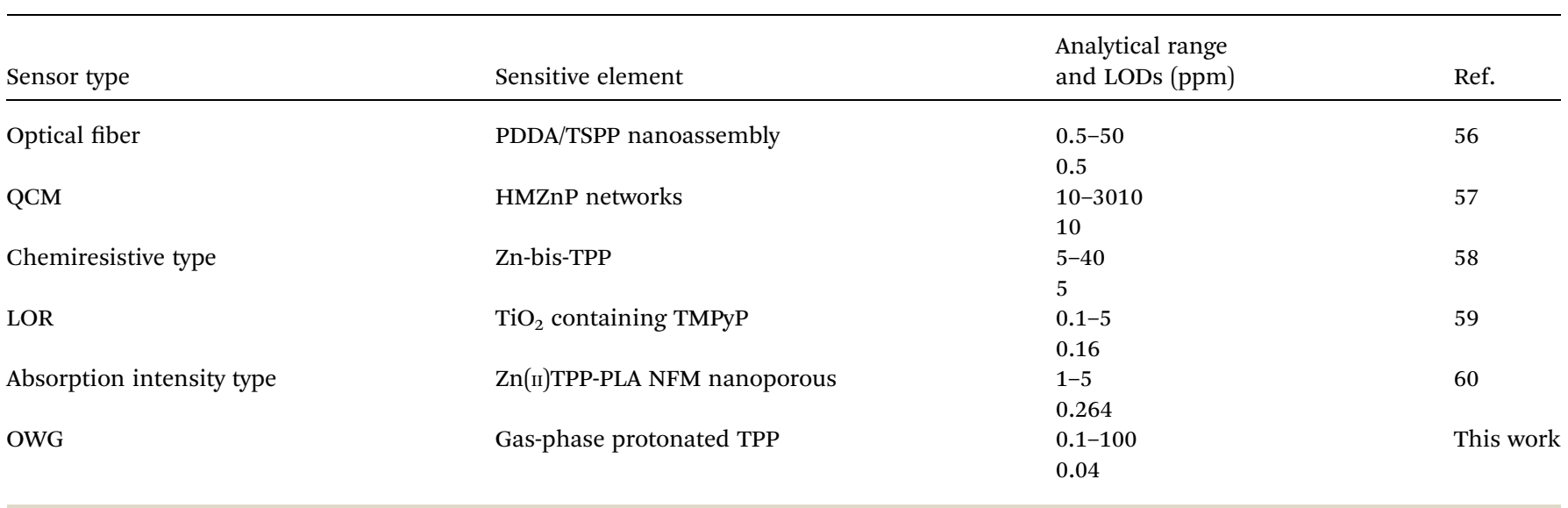

were observed in the film topography after exposure of the film containing surface aggregates (by exposure of $\mathrm{H}_{2} \mathrm{~S}$ ) to $\mathrm{NH}_{3}$ gas (see Fig. 5e and f); the vertical nanorods disappeared and the surface of the film became smooth. This indicates that the aggregates dispersed after exposure to $\mathrm{NH}_{3}$.

\subsection{Gas sensing measurement}

The gas sensing property of the protonated TPP thin film OWG sensor was evaluated based on the deprotonation of TPP. The protonated film turned from red to blue after exposure to $\mathrm{NH}_{3}$ gas, as shown in Fig. 6. When the TPP film was exposed to $\mathrm{H}_{2} \mathrm{~S}$ gas, significant changes were observed in the visible region, with the Soret band of the TPP film undergoing a red shift from $436 \mathrm{~nm}$ to $460 \mathrm{~nm}$ and two new Q bands emerging at $364 \mathrm{~nm}$ and $677 \mathrm{~nm}$, respectively. At the same time, when the same film was exposed to $\mathrm{NH}_{3}$ gas, the Soret band underwent a blue shift from $460 \mathrm{~nm}$ to $436 \mathrm{~nm}$, with the two Q bands splitting into four $\mathrm{Q}$ bands; these are characteristic features of the free-base TPP monomer. The absorbance changes are listed in Table 2.

For the OWG sensor, as mentioned above, the thickness, refractive index, porosity, and attenuation of the film are the major factors that affect its intensity. A sensing film with higher refractive index, thickness, and porosity, and lower attenuation reveals higher sensitivity. ${ }^{54}$ We can see from Table 2 that the refractive index decreased from 1.7757 to 1.6302 due to the decrease in thickness. The remarkable decrease in the refractive index in the excitation of the waveguide mode in the protonated TPP film OWG, which enhanced the inherent sensitivity of the sensor in accordance with the simulated results shown in Fig. 7. Besides, the $\mathrm{NH}_{3}$ gas molecule was small enough to penetrate the protonated TPP pores several tens to hundred nanometers in diameter.

The reversible responses of the protonated TPP thin film OWG sensor to $\mathrm{NH}_{3}$ gas at various concentrations were studied, and the results are presented in Fig. 7. The signal attenuations, defined as $\alpha=-10 \log \left(I_{\text {ammonia }} / I_{\text {hydrogen sulfide }}\right),{ }^{55}$ corresponding to $100,10,1$, and $0.1 \mathrm{ppm}$ of $\mathrm{NH}_{3}$, were $4.07,1.01,0.57$, and 0.24 $\mathrm{dB}$, respectively. The injection of air from the surrounding environment caused a slight disturbance in the signal; however, the disturbance was significantly smaller than the change in the signal in the presence of $100 \mathrm{ppb} \mathrm{NH}_{3}$.

The reaction mechanism is shown in Fig. 7. Initially, the $\mathrm{H}_{2} \mathrm{~S}$ gas molecules are adsorbed onto the TPP film OWG primarily in the form of J-aggregates. The exposure of the protonated TPP film OWG sensor to $\mathrm{NH}_{3}$ gas leads to the deprotonation of $\mathrm{H}_{2} \mathrm{TPP}^{2+}$, which results in its return to the monomeric state. TPP becomes protonated again when it is exposed to $\mathrm{H}_{2} \mathrm{~S}$ gas. It is clearly seen from Fig. 7 that TPP can be reversibly converted into $\mathrm{H}_{2} \mathrm{TPP}^{2+}$ through protonation and deprotonation reactions in the presence of $\mathrm{H}_{2} \mathrm{~S}$ and $\mathrm{NH}_{3}$, respectively. Repeated exposure of the TPP thin film to $\mathrm{NH}_{3}$ and $\mathrm{H}_{2} \mathrm{~S}$ causes the formation of $\left(\mathrm{NH}_{4}\right)_{2} \mathrm{~S}$ as a by-product. However, $\left(\mathrm{NH}_{4}\right)_{2} \mathrm{~S}$ can be removed by washing the film with water. The protonated TPP film OWG sensor exhibited a strong and fast response, complete reversibility, and excellent repeatability even after several sensing cycles (see Fig. 7). These results confirm that the gas-phase protonated TPP film OWG sensor is a suitable material for the detection of $\mathrm{NH}_{3}$ gas.

A calibration curve of absorbance as a function of $\mathrm{NH}_{3}$ gas concentration is plotted in Fig. 8. This curve was obtained by plotting the signal $(\alpha)$ of the sensor against the concentration of $\mathrm{NH}_{3}$ gas. The value of $\alpha=\log \left(\Delta I_{\text {hydrogen sulfide }} / I_{\text {ammonia }}\right)$ is plotted on the ordinate axis; here, $I_{\text {hydrogen sulfide }}$ is the change in the initial intensity of the output light after injection of $\mathrm{H}_{2} \mathrm{~S}$ gas and $I_{\text {ammonia }}$ is the highest output light intensity either before or after the injection of $\mathrm{NH}_{3}$ gas into the flow chamber. The relationship between the signal and $\mathrm{NH}_{3}$ concentration was found to be linear. From the data, it can be observed that the response of the sensor to $\mathrm{NH}_{3}$ gas was strongly dependent on $\mathrm{NH}_{3}$ gas concentration, with the response being linear in the range of $\mathrm{NH}_{3}$ concentrations from $100 \mathrm{ppb}$ to $100 \mathrm{ppm}(A=(2.59 \pm$ $\left.0.019)+(0.32 \pm 0.013)\left[\mathrm{NH}_{3}\right], R=0.99\right)$.

Table 3 provides a comparison of the ammonia detection performance of the developed sensor with those of the other porphyrin sensors in terms of analytical range and limit of detection (LOD), revealing that the gas-phase protonated TPP film OWG sensor featured a much lower detection limit than 
other types of porphyrin sensors did. Furthermore, compared to other sensors, the one described herein was easier to fabricate and was reusable for $\mathrm{NH}_{3}$ detection.

\section{Conclusions}

In summary, TPP monomers underwent protonation when they were exposed to acidic gases. $\mathrm{H}_{2} \mathrm{~S}$ gas acted as a proton donor to the TPP monomers in gas-phase owing to its proton richness, and the sensor was characterized by ${ }^{1} \mathrm{H}$ MNR and AFM. Here, a novel gas-phase protonated TPP film OWG sensor for $\mathrm{NH}_{3}$ gas detection was demonstrated. The sensor was highly sensitive toward $\mathrm{NH}_{3}$ gas, and sensitivity to other amine gases were smaller (see Fig. S1 $\dagger$ ) then that of $\mathrm{NH}_{3}$. The sensing mechanism was found to be strongly dependent on the changes in the TPP film morphology, which in turn led to changes in the film absorbance. The enhanced absorbance was associated with the presence of aggregate structures on the protonated TPP film surface, and was examined in terms of the changes detected in the reflected light intensity. We successfully detected $\mathrm{NH}_{3}$ gas at a concentration as low as 0.1 ppm. Furthermore, the sensor exhibited a high sensitivity, reversible response, and fast response-recovery times. In addition, the sensor was found to be both inexpensive and reusable and should therefore find wide application in environmental monitoring and detection of poisonous gases in agricultural, industrial, and medical fields. This sensor system can also be utilized as a novel bio-sniffer for sensitive and selective detection of amines found in the environment or those produced by the human body.

\section{Conflicts of interest}

There are no conflicts to declare.

\section{Acknowledgements}

This work was supported by the National Natural Science Foundation of China (Grant No. 21765021).

\section{References}

1 Y. Ding, W. H. Zhu and Y. Xie, Chem. Rev., 2016, 117, 2203. 2 J. H. Lee, H. Jintoku, Y. Okazaki, T. Sagawa, M. Takafuji and H. Ihara, Sol. Energy Mater. Sol. Cells, 2015, 140, 428.

3 M. C. Tsai, C. L. Wang, C. Y. Lin, C. L. Tsai, H. J. Yen, H. C. You and G. S. Liou, Polym. Chem., 2016, 7, 2780.

4 P. Gao, Z. Chen, Z. Zhao-Karger, J. E. Mueller, C. Jung, S. Klyatskaya, T. Diemant, O. Fuhr, T. Jacob, R. J. Behm, M. Ruben and M. Fichtneret, Angew. Chem., 2017, 56, 10341.

5 K. Liu, R. Xing, C. Chen, G. Shen, L. Yan, Q. Zou, G. Ma, H. Mçhwald and X. Yan, Angew. Chem., 2015, 127, 510.

6 A. D. Schwab, D. E. Smith, C. S. Rich, E. R. Young, W. F. Smith and J. C. D. Paula, J. Phys. Chem. B, 2003, 107, 11339.

7 D. D. La, A. Rananaware, M. Salimimarand and S. V. Bhosal, ChemistrySelect, 2016, 1, 4430.
8 G. Zhu, Y. Li, H. Zhu, H. Su, S. H. Chan and Q. Sun, ACS Catal., 2016, 6, 6294.

9 F. Song, P. Ma, C. Chen, J. Jia, Y. Wang and P. Zhu, J. Colloid Interface Sci., 2016, 474, 51.

10 K. K. Ng, J. F. Lovell, A. Vedadi, T. Hajian and G. Zheng, ACS Nano, 2013, 7, 3484.

11 G. M. Whitesides and B. Grzybowski, Science, 2002, 295, 2418.

12 J. Wang, Z. Yong, W. Liang, Z. Na, R. Cao, K. Bian, A. Leanne, R. E. Haddad, F. Bai and H. Fan, Nano Lett., 2016, 16, 6523.

13 P. Roberto, N. Sara, M. Donato, S. Manuela and D. N. Corrado, Chem. Rev., 2017, 117, 2517.

14 H. Takechi, A. Canillas, J. M. Ribó and H. Watarai, Langmuir, 2013, 29, 7249.

15 H. Nagatani and H. Watarai, Anal. Chem., 1996, 68, 1250.

16 S. Wada, K. Fujiwara, H. Monjushiro and H. Watarai, J. Phys.: Condens. Matter, 2007, 19, 1501.

17 S. Jung, J. Seo and S. K. Shin, J. Phys. Chem. A, 2010, 114, 11376.

18 N. C. Maiti, A. S. Mazumdar and N. Periasamy, J. Phys. Chem. B, 1998, 102, 1528.

19 L. Zheng and S. S. Kenneth, ACS Sens., 2016, 1, 1330.

20 P. L. Smock, T. A. Orofino, G. W. Wooten and W. S. Spencer, Anal. Chem., 1979, 51, 505.

21 J. F. Giuliani, H. Wohltjen and N. L. Jarvis, Opt. Lett., 1983, 8, 54.

22 K. Tiefenthaler and W. Lukosz, Opt. Lett., 1984, 10, 137.

23 J. Qin, Y. Zhang, X. Liang, C. Liu, C. Wang, T. Kang, H. Lu, L. Zhang, P. Zhou, X. Wang, B. Peng, J. Hu, L. J. Deng and L. Bi, ACS Photonics, 2017, 4, 1403.

24 A. Yamaguchi, K. Hotta and N. Teramae, Anal. Chem., 2009, 81, 105.

25 K. Hotta, A. Yamaguchi and N. Teramae, ACS Nano, 2012, 6, 1541.

26 A. R. Chris, B. S. Stephanie, J. F. Mark, P. G. Joel and S. L. France, Anal. Chem., 1999, 71, 433.

27 M. Palanisamy and S. J. Abraham, Sens. Actuators, B, 2012, 174, 74 .

28 American Industrial Hygiene Association, Ammonia, Hygienic Guide Series, Detroit, Michigan, 1971.

29 Health and safety executive, Guidance note EH40/93 occupational exposure limits, HMSO, London, 1993.

30 R. Nieto, A. G. Calder, S. E. Anderson and G. E. Lobley, J. Mass Spectrom., 2015, 31, 289.

31 A. Yimit, A. G. Rossberg, T. Amemiya and K. Itoh, Talanta, 2005, 65, 1102.

32 K. Hotta, A. Yamaguchi and N. Teramae, ACS Nano, 2012, 6, 1541.

33 P. Muthukumar and S. A. John, Sens. Actuators, B, 2012, 174, 74.

34 L. Q. Nguyen, P. Q. Phan, H. N. Duong, C. D. Nguyen and L. H. Nguyen, Sensors, 2013, 13, 1754.

35 J. Enon, A. Tuantranont, T. Kerdcharoen and C. Wongchoosuk, RSC Adv., 2017, 7, 16885.

36 X. Liu, N. Chen, B. Han, X. Xiao, G. Chen, I. Djerdj and Y. Wang, Nanoscale, 2015, 7, 14872. 
37 J. Wei, B. Liang, Q. Cao, C. Mo, Y. Zheng and X. Ye, RSC Adv., 2017, 7, 33510.

38 Z. Zhang, J. Zhu, Q. Han, H. Cui, H. Bi and X. Wang, Appl. Surf. Sci., 2014, 321, 404.

39 R. Salmio, J. Saarinen, J. Turunen and A. Tervonen, Appl. Phys. Lett., 1995, 66, 917.

40 H. Ablat, A. Yimit, M. Mahmut and K. Itoh, Anal. Chem., 2008, 80, 7678.

41 P. Nizamidin, A. Yimit, A. Abdurrahman and K. Itoh, Sens. Actuators, B, 2013, 176, 460.

$42 \mathrm{H}$. Nishihara, M. Haruna and T. Suhara, Integrated Optics, 1st edn, 1987.

43 H. Yanagi, K. Itoh, M. Murabayashi and Z. M. Qi, J. Lightwave Technol., 2002, 18, 1106.

44 A. Yimit, K. Itoh and M. Murabayashi, Sens. Actuators, B, 2003, 88, 239.

45 P. Nizamidin, A. Yimit, J. D. Wang and K. Itoh, Thin Solid Films, 2012, 520, 6250.

46 P. Nizamidin, A. Yimit, A. Abdurrahman and K. Itoh, Sens. Actuators, B, 2011, 76, 460.

47 J. Ma, W. Zhang, Z. Li, Q. Lin, J. Xu and Y. Han, Cryst. Growth Des., 2016, 16, 1942.

48 S. I. T. Kondo and I. Abe, Absorb Science, ed. G. X. Li, Chemical Industry Press, Beijing, 3rd edn, 2003.
49 L. A. Curtiss, C. Jones, G. W. Trucks, K. Raghavachari and J. A. Pople, J. Chem. Phys., 1990, 93, 2537.

50 J. S. Brian and R. Leo, J. Phys. Chem., 1991, 95, 10551.

51 Y. Zhang, M. X. Li, M. Y. Lü, R. H. Yang, F. Liu and K. A. Li, J. Phys. Chem. A, 2005, 109, 7442.

52 Y. Saegusa, T. Ishizuka, Y. Shiota, K. Yoshizawa and T. Kojima, J. Org. Chem., 2017, 82, 322.

53 P. Kalimuthu and S. A. John, ACS Appl. Mater. Interfaces, 2010, 2, 3348.

54 N. Patima, Y. Abliz and I. Kiminori, New J. Chem., 2016, 40, 295.

55 N. Hiroshi, H. Masamitsu and S. Toshiaki, Integrated Optical Circuit, Science Press, Beijing, 2005.

56 S. Korposh, S. Kodaira, R. Selyanchyn, F. H. Ledezma, S. W. James and S. W. Lee, Opt. Laser Technol., 2018, 101, 1.

57 J. H. Park, J. H. Ko, S. Hong, Y. J. Shin, N. Park, S. Kang, S. M. Lee, H. J. Kim and S. U. Son, Chem. Mater., 2015, 27, 5845.

58 K. Garg, A. Singh, C. Majumder, S. K. Nayak, D. K. Aswal, S. K. Gupta and S. Chattopadhyay, Org. Electron., 2013, 14, 1189.

59 D. Tiwari, K. Mullaney, S. Korposh, S. W. James, S. W. Lee and R. P. Tatam, Sens. Actuators, B, 2017, 242, 645.

60 M. Hu, W. Kang, Z. Li, S. Jie, Y. Zhao, L. Li and B. Cheng, J. Porous Mater., 2016, 23, 911. 